\title{
Hemodialysis Adequacy Sacrificed for Business: A Qualitative Study
}

\author{
Vajihe Biniaz, ${ }^{1}$ Hossein Karimi Moonaghi, ${ }^{1,}{ }^{*}$ Razieh Froutan, ${ }^{1}$ and Abbass Ebadi ${ }^{2}$ \\ ${ }^{1}$ Department of Medical Surgical Nursing, School of Nursing and Midwifery, Mashhad University of Medical Sciences, Mashhad, Iran \\ ${ }^{2}$ Department of Medical Surgical Nursing, Baqiyatallah University of Medical Sciences, Tehran, Iran \\ "Corresponding author: Hossein Karimi Moonaghi, Professor, School of Nursing and Midwifery, Mashhad University of Medical Sciences, Doctora Intersection, Mashhad, Iran. \\ Tel: +98-9153155214, Fax: +98-5138597313, E-mail: karimih@mums.ac.ir
}

Received 2018 March 08; Accepted 2018 April 20.

\begin{abstract}
Background: Dialysis adequacy is a predictor for mortality and morbidity in patients undergoing hemodialysis. Previous studies pinpointed several factors as barriers to adequate dialysis. However, there is a scarcity of studies investigating the experiences of patients undergoing hemodialysis and health care providers (e g, dialysis nurses and nephrologists) with regards to high-quality dialysis barriers. The current study aimed at gaining a deeper understanding regarding the experiences of patients undergoing hemodialysis and dialysis professionals about the subjective barriers to hemodialysis adequacy.

Methods: The current study was conducted using the conventional content analysis method; 19 patients undergoing hemodialysis, 2 hemodialysis caregivers, 2 hemodialysis nurses, and 2 nephrologists were included and interviewed.

Results: Based on the obtained data, 993 initial codes were extracted under four categories: barrier of self, social support insufficiency, hemodialysis mafia, and supervision weakness.

Conclusions: Patients undergoing hemodialysis and health care providers have different experiences compared with what is mentioned in textbooks about barriers to high-quality dialysis. The findings highlight the need for immediate re-examination and preparation of the standards for the quality of hemodialysis, as well as attention and focus on non-physiological barriers to dialysis adequacy.
\end{abstract}

Keywords: Hemodialysis, Dialysis Adequacy, Kt/V, Content Analysis

\section{Background}

Dialysis adequacy is defined as equalizing the condition of patients undergoing hemodialysis with the condition of healthy people in terms of kidneys functioning (1). Therefore, the quality of hemodialysis is associated with the patient's general health, less complications of renal failure, and consequently, higher life span (2).

According to the findings of previous studies, dialysis adequacy is a predictor for mortality and morbidity in patients undergoing hemodialysis, and patients undergoing adequate dialysis have a lifespan equal to that of patients with renal transplant (3). On the other hand, inadequate hemodialysis increases the patient's need for more prolonged or frequent hemodialysis, reduces the quality of life, imposes additional treatment costs on the national health system, and promotes the risk of transmitting fatal infectious agents such as hepatitis $B$ and $C$ viruses and other blood contaminating agents among in patients (4, 5).

The results of studies conducted in Iran on dialysis quality revealed low dialysis adequacy in more than half of patients (6-8). Unlike other countries, the length of hospital stay in Iran after starting dialysis is increasing every year (9), which greatly increases the costs imposed to patients undergoing dialysis in a covert manner (10).

The high prevalence of symptoms such as fatigue (11), anorexia (12), sleep disorders (13), nausea and vomiting (14), peptic ulcer disease (15), itching (16), blood coagulation disorders (17), hyperparathyroidism (18), infection (19), dysgeusia (20), and blood pressure fluctuations due to inadequate dialysis can undermine the quality of life. Previous studies pinpointed several factors as barriers to adequate dialysis, namely patient - related factors (e g, hypotension, intradialytic symptoms, treatment time missed due to noncompliance or transportation problems, duration $<4$ hours, blood flow rate (BFR) $<350 \mathrm{~mL} /$ minute, patient weight $>100 \mathrm{~kg}$, and delivered BFR $50 \mathrm{~mL} /$ minute less than the prescribed BFR) and technical factors (e g, dialysis prescription, type of vascular access, clotting, and dialyzer reuse) (21-23). However, there is a scarcity of studies investigating the experiences of patients undergoing hemodialysis and health care providers (e g, dialysis nurses and nephrologists) with regards to high - quality dialysis 
barriers. Accordingly, it was sought to gain a deeper understanding regarding the experiences of patients undergoing hemodialysis and dialysis professionals about the subjective barriers to hemodialysis adequacy.

\section{Methods}

Herein, the subjective perceptions and experiences of the study participants regarding the barriers to adequate hemodialysis were addressed by applying the conventional content analysis method. The study population consisted of 19 patients undergoing hemodialysis, 2 hemodialysis caregivers, 2 hemodialysis nurses, and 2 nephrologists. All the participants were willing to participate in the study, had no speech or hearing deficiencies, spoke fluent Persian, aged $>18$ years, and had basic education, and no history of drug or alcohol abuse or history of hospital admission due to psychological problems in the past year. Patients had started hemodialysis therapy at least 12 weeks before the study initiation (3 - 4 hours each session). Hemodialysis nurses and nephrologists with related work experience for more than three years were also included in the study. To have maximum diversity in the demographic and phenomenological variables, purposive sampling was continued until data saturation.

After gaining approval of the Ethics Committee of Mashhad University of Medical Sciences (code: IR.MUMS.REC.1395.309) and obtaining informed consent from the participants, following explaining the research objectives, the roles of researchers and participants, and the methods of data collection and recording, providing a quiet and peaceful environment during the interviews, giving the participants the right to withdraw from the study at any time, assuring confidentiality of the data, and providing the results to the participants in case they sought them, the participants were separately interviewed face - to - face based on the unstructured interview method on general and more specific queries as follows: 'describe your experiences on a hemodialysis day' and 'what barriers did you experience to adequate dialysis?'. Each interview lasted 40 - 110 minutes. With the consent of the participants, the interviews were recorded, and at the end of each interview, the participants were informed about the likelihood of another meeting to complete and clarify the interviews. Although the participants agreed to it, a second interview was required only in two cases. Demographic characteristics of the participants are shown in Table 1.

After the interviews, each recorded interview was played several times, and using MaxQda software, verbatim transcripts were created and numbered by the researcher. Data saturation was reached after 25 interviews.
Sampling lasted about 14 months, from the beginning of June 2016 until the end of July 2017. Data analysis was performed using the Hsieh method (24). In this method, codes and categories are extracted from the raw materials inductively and systematically.

First, in order to understand how the participants felt, their statements were read repeatedly (step 1 ). Then, the key phrases were highlighted (step 2) and units of meaning and codes were extracted (step 3 ). The extracted codes were organized into categories based on conceptual and semantic similarities (step 4). Then, the categories were integrated into larger categories (step 5). Finally, themes or abstract categories were extracted by the comparison of categories and subcategories (step 6).

The regular presence of the researcher in different working shifts at the hemodialysis ward and her long time involvement with the subject, as well as selection of the participants with maximum diversity (in terms of age, gender, occupational status, marital status, financial stats, and history of hemodialysis) bolstered the validity of the study. Member check and rectifying the codes that did not accurately describe the point of view of the participants (based on their own opinion) improved the reliability of the study. To promote confirmability, the researcher first recorded her own presumptions regarding the answers and tried not to emphasize on them. Finally, dependability was assured by immediate transcription of the interviews and the use of external check and reviewing the data. Further, with precise delineation of the study procedures and stages, the readers were able to follow the steps and appraise them.

In the current study, the Guba and Lincoln criteria were adopted to assess the validity and reliability of the data (25). The believability of the dataset was ensured through the researcher's long - term engagement in collecting and analyzing the data and the employment of revisions and reviews conducted by the research associates and participants. To establish the reliability of the data, after being heard, implemented, and analyzed, the interviews were peer-reviewed (by an expert in qualitative studies who was not involved in the study). In addition, auditing was used to achieve data neutrality and objectivity. Based on the previous experiences of the researcher in hemodialysis wards, she tried to avoid bias and did not study any similar literature until the completion of the analysis process. To ensure the transferability of the study, the research was fully explained and the context and stages of the study were fully described to the subjects by the researcher. Furthermore, it was attempted to select subjects with diversity in terms of demographic characteristics. Since the interviews were in Persian, the spoken words of the participants were quoted indirectly. 


\begin{tabular}{|c|c|c|c|c|}
\hline Participant Number & Gender - Age (year) & Hemodialysis Vintage (mo) & Education & Interview Duration (min) \\
\hline $\mathbf{1}$ & F- 49 & 171 & Primary or secondary & 53 \\
\hline 2 & F- 73 & 40 & Primary or secondary & 41 \\
\hline 3 & $F-42$ & 32 & Primary or secondary & 49 \\
\hline 4 & $F-52$ & 41 & College or university & 43 \\
\hline 5 & F- 76 & 75 & Primary or secondary & 40 \\
\hline 6 & F-52 & - & College or university & 16 \\
\hline- & F- 65 & 23 & Primary or secondary & - \\
\hline 7 & F- 29 & - & College or university & 18 \\
\hline 8 & $M-70$ & 69 & College or university & 51 \\
\hline 9 & M- 66 & 120 & College or university & 112 \\
\hline 10 & M - 39 & 69 & College or university & 47 \\
\hline 11 & $F-30$ & 12 & College or university & 47 \\
\hline 12 & $F-30$ & 45 & College or university & 48 \\
\hline 13 & F-26 & 50 & College or university & 46 \\
\hline 14 & F-33 & 18 & College or university & 45 \\
\hline 15 & F-37 & 24 & College or university & 41 \\
\hline 16 & F-35 & 12 & College or university & 42 \\
\hline 17 & $F-35$ & 16 & College or university & 53 \\
\hline 18 & $F-40$ & 192 & College or university & 61 \\
\hline 19 & F- 72 & 40 & Primary or secondary & 40 \\
\hline 20 & $M-30$ & 72 & Primary or secondary & 67 \\
\hline 21 & $M-37$ & 75 & Primary or secondary & 75 \\
\hline 22 & M-33 & 75 & Primary or secondary & 63 \\
\hline 23 & $M-47$ & 75 & Primary or secondary & 92 \\
\hline 24 & M - 56 & 75 & Primary or secondary & 33 \\
\hline 25 & M - 49 & - & Primary or secondary & 16 \\
\hline
\end{tabular}

\section{Results}

The mean age of the participants was $44.48 \pm 15.97$ years (ranged 23 to 76) and the mean duration of hemodialysis in the patients was 71.9 \pm 68.6 months (ranged 12-264); $61 \%$ of the total participants were female and $37 \%$ were employed. Diabetes and hypertension were the leading causes of chronic kidney disease in the patients. From the obtained data, 993 initial codes were extracted under four categories of barrier of self, social support insufficiency, hemodialysis mafia, and supervision weakness. Each of these categories comprised of some subcategories. Table 2 illustrates the process of shaping these categories and subcategories.

\subsection{Category of Barrier of Self}

Participants in the current study considered some features, behaviors, and individual characteristics of patients undergoing hemodialysis as a barrier to efficient dialysis. This category contained some subcategories going under the titles of passive behavior, information defects, treatment non - adherence, and non - acceptance of dialysis.

\subsection{Passive Behavior}

Based on the experiences of the participants in the study, one of the barriers to quality dialysis is lack of demanding, criticism, and questioning in patients undergoing hemodialysis classified as passive behavior. Participant No. 10 stated: "Patients themselves do not care about their dialysis quality, they're just looking for weight loss; they endure so much pain that they lose the desire to live. 


\begin{tabular}{l|l}
\hline Table 2. Study Categories and Subcategories \\
\hline Emerged Categories & Subcategories \\
\hline \multirow{4}{*}{ Barrier of self } & Passive behavior \\
\cline { 2 - 2 } & Information deficiency \\
\cline { 2 - 2 } & Treatment non - adherence \\
\cline { 2 - 2 } Social support insufficiency & Non - accepting dialysis \\
\hline \multirow{4}{*}{ Hemodialysis mafia } & Lack of support from the family \\
\cline { 2 - 2 } & Non - support of insurer organizations \\
\hline & Blackwashing \\
\cline { 2 - 2 } & Healing superstition \\
\cline { 2 - 2 } & Betraying confidant \\
\cline { 2 - 2 } & Select patient \\
\hline \multirow{4}{*}{ Supervision weakness } & Merchant inspector \\
\cline { 2 - 2 } & Rapid dialysis \\
\cline { 2 - 2 } & Delayed and unapprised payment \\
\cline { 2 - 2 } & Incompatibility with the standard \\
\cline { 2 - 2 } & Obsolete machines \\
\hline
\end{tabular}

They'd like to die sooner, so they'd never complain. Although they know their quality of dialysis is low, they won't look into it".

\subsection{Information Deficiency}

Based on the experiences of the participants in the study, limited knowledge about the recommended diet, lack of information on how to use the drugs and their side effects, unawareness about the disease symptoms and self care behaviors, and lack of knowledge about management of the complications of dialysis can undermine the quality of dialysis. Participant No. 8 asserted: "Most patients have little information and don't know what to eat and how to eat it or how or when to take their meds. In addition, nurses and doctors don't have the patience to train and explain such stuff".

\subsection{Treatment Non-Adherence}

Based on the participants' experiences, one of the barriers to dialysis quality is the mismatch between the behaviors of the patients undergoing hemodialysis and health therapeutic recommendations. Participant No. 8 added: "I can't avoid all the things they tell me not to eat, but I try to curb them. I take my drugs, but not as regularly as I'm supposed to because my children say I'm undergoing dialysis and I don't need any medications".

\subsection{Not Accepting Dialysis}

Based on the current study data, failure to accept dialysis and lack of adjustment with its undeniable stresses can be considered as a barrier to efficient dialysis. Participant No. 15 remarked: "I attend the dialysis sessions because my family forces me to. It has taken everything from me. Once I went on a 12 - day trip and I didn't undergo dialysis. I felt great; I didn't have nausea or diarrhea. I normally have watery stool. I am not even depressed. I did not want to go to dialysis again, but my family forced me to. I'm sleeping all the time at home".

\subsection{The Category of Social Support Insufficiency}

Participants had experienced insufficient social support as one of the barriers to adjustment with the disease, effective disease management, and quality of dialysis. This inadequate support was perceived from the family, friends, care givers, and even the society. This category encompasses lack of support from the family and insurance organizations.

\subsection{Lack of Support from the Family}

According to the participants' experiences, lack of endorsement from the family can hinder efficient dialysis by creating a negative subjective feeling of lack of belonging and acceptance, lack of interest, and understanding that there is no supporter to receive help from when required. Participant No. 14 remarked: "My husband's family urges him to divorce me and get married again. They tell him not to waste his time for me. They tell him to go and find a healthy woman. Since dialysis, my husband has changed a lot; he's nervous and doesn't care about me. Although he owns a car, he never gives me a ride to the dialysis center". Participant No. 22 said: "My wife does not care much about me. I tell her to make the food in a certain way, which is better for my health status, but she doesn't seem to care. My parents are very attentive to me, but she is not". Participant No. 1 also stated: "I haven't got a father and my mum has never supported me. My brothers and sisters know about my disease, but they're too busy to worry about me".

\subsection{Lack of Support from Insurance Organizations}

The participants accounted lack of support for hemodialysis patients from some organizations such as insurance agencies, the Social Security Agency, and the Charity Association for the Protection of Patients with Renal Diseases as a barrier to high - quality dialysis. Participant No. 25 asserted: "They've excluded some medicines from the insurance coverage list. Well, we haven't got the money to buy these expensive drugs, so we just let go of it. And now they say health insurance is no longer effective. I don't know what to do. How should we pay for the doctor's visit and the drugs! The Association for the Protection of Patients with Renal Diseases should manage such things, but they're only after absorbing more patients". A participated nephrologist pointed out: "The major challenge is the mismanagement of medications; 
Social Security stated that some medications are only given on a monthly basis. Whereas, a patient should visit the treating physician twice to receive a prescription and should seek the medicines twice".

\subsection{The Category of Hemodialysis Mafia}

The experiences of the participants with respect to barriers to quality dialysis pointed to the existence of invisible networks touting for a profitable business. This category includes the subcategories of blackwashing, healing superstition, betraying confidant, and select patient.

\subsection{Blackwashing}

According to the participants, accusing the dialysis centers in the city for nonadherence to the standards, in order to prevent the patients from referring to other centers, and thereby, congestion of patients in a particular center with poor - quality dialysis services is another barrier to adequate hemodialysis.

Participant No. 23 added: "They narrate bad stories about stuff working in other centers, so no one would ever dare to go there. They say those places have poor hygienic conditions; they are dirty, and one might get blood - borne diseases such as hepatitis. So, we've got no other choice than staying here. All their devices are old and we don't receive proper care".

\subsection{Healing Superstition}

Attracting the trust of patients by taking advantage of their religious beliefs about the names of Imams, in order to persuade the patient into a certain dialysis center and causing congestion in some centers, and subsequently, shortening the dialysis sessions were considered a barrier to adequate hemodialysis.

A head nurse said: "Unfortunately, they take advantage of the names of Imams and manipulate patients' emotions with a series of issues, such as using the names of Imams for the centers. For example, although they do not observe any standards in their practices, they tell the patients that this Imam has a particular attention toward this center and he will heal you. Sometimes, they call me asking what we should do with a particular patient, and I say the doctor said patients are healed there by Imams; how come this patient is deteriorating!"

\subsection{Betraying the Confidence}

Attracting patients to private dialysis centers using donations given to non - governmental organizations (NGOs) for all patients undergoing hemodialysis was another experience of the current study participants; it increased the number of waiting patients, shortened dialysis time, and reduced quality of dialysis in some centers.
Participant No. 10 asserted: "Some of the centers tell the patient that if you refer us, we will provide you the car transfer facilities; we don't pay for it; it is the donors and charities that pay for all the patients. In the past, the money was spent on equipment and stationeries".

\subsection{Discrimination at Admission}

Picking out younger patients with a better health status without any underlying diseases irrespective of the geographical divisions are the other strategies followed by some dialysis centers with economic purposes in order to gain more profit. These policies cause congestion of patients in some centers and shorter dialysis time.

Participant No. 20 remarked: "The policy of the Ministry of Health is to increase dialysis centers based the geographical regions; therefore, patients should refer to the nearest centers to reduce the commuting problems. But, (some of the centers) to increase their patients tell them to go to another center, which is far away from their home. For example, we had a patient who lived in Tabarsi Street and there was a dialysis center, but they sent him to Seeman Street to a certain center. In fact, there is a mafia that plans everything in order to make some people gain more". Participant No. 10 claimed: "In my opinion, giving authorization to nephrologists to establish dialysis centers is totally wrong. For example, a doctor who was OK in every way before, now that she owns a center she looks for top and young patients without any underlying diseases to bring them to her center and she turns down old and complicated patients to gain more profit with less problems".

\subsection{The Category of Weakness of Supervision}

One of the obstacles to high - quality dialysis was the lack of timely and accurate monitoring of the dialysis process, the implementation of dialysis standards, the type of payment to dialysis units; the accuracy and efficiency of dialysis devices, and merchant inspector, rapid dialysis, delayed and unevaluated payment, and obsolete equipment were its subcategories.

\subsection{Merchant Inspector}

Participants claimed that the inspectors should be unbiased when investigating the quality and process of hemodialysis, but they are either importers of dialysis equipment or they are the shareholders of one or more dialysis centers. The interest of inspectors and observers leads to biased supervision and non - adherence to the scientific guidelines for dialysis.

Participant No. 20 said: "It's interesting that when inspectors go to other dialysis centers, they are completely by the numbers, but it's not the same when they go to 
their own center or to the ones that they are the stakeholders. They hold interest. Patient in this system is a source of income. Dialysis should get out of this mafia to be improved".

\subsection{Rapid Dialysis}

Participants in the study noted shortened standardized time of dialysis session due to increase the number of patients who should be dialyzed with the same device in the same day.

Participant No. 23 said: "My dialysis is never complete; that is, I never receive dialysis for four hours. They want to disconnect the device sooner to bring in the next group. And to compensate it, they increase the flow rate as a results of which either my blood pressure or sugar drops or I experience muscle spasm".

Nephrologist No. 25 said: "In abroad, patients undergo five hours dialysis, while in some of our hospitals, dialysis lasts only for three hours, although the dialysis time of less than four hours is not standard, it is performed for economic purposes and due to limited number of dialysis machines.

\subsection{Delayed and Unapprised Payment}

Lack of timely payment and commitment to the evaluation process and quality of dialysis are other barriers to high - quality dialysis. Participant No. 20 remarked: "Insurance organization only pays the centers based on the number of patients. Meaning, quality doesn't matter. The center with best equipment earns the same as those with out of - date machines".

Participant No. 10 said: "The insurance organization postposes our payments for about six months. It leads the centers not to use high - quality equipment. With the inflation we have, the value of the money we've spent grows less. And then, they stop paying for a period time".

A participating nephrologist added: "In Iran, there's no supervision over the quality of services. And there's no yardstick to evaluate the services we are purchasing, such as if the service meets certain criteria, it is acceptable. In many centers, the provided services are below the standard, which cause irreparable harms to both the patient's health and the economy.

\subsection{Non-Compliance with the Standard}

The participants viewed no compliance with the standards and scientific guidelines regarding the use of suitable filters and flow rate for each patient, lack of commitment to dialysis standards, lack of scheduling dialysis based on the patient's test results, non - compliance with the physician advice, and inappropriate weight gain as other barriers to adequate dialysis.
Participants No. 21 stated: "I've notified the nurses time and time again that my doctor recommended that I should use small - size filters and not to lose much weight, but they use whatever size filter they have and they tell me I have excess weight”. A nephrologist added: “They don't use the filter based on the patient's need, but based on what they have".

\subsection{Obsolete Machines}

Considering the barriers to adequate dialysis, the participants hinted about the lack of calibration of dialysis machines, immediate troubleshooting, and timely modernization and upgrading the old equipment that result in faster depreciation of dialysis machines.

Participant No. 7 pointed out: "They use old machines. They're so run - down that I don't think they can perform properly. The alarm goes off all the time, but they let it continue working”. Participant No. 10 remarked: "All the machines are flawed and whatever parameters you give into it, it does what it did. The technician who does the calibration charges 48.2 US \$, so they don't ask him to come, or they ask him to come once every season".

\section{Discussion}

The results of the current study showed that patients undergoing hemodialysis, dialysis nurses, and nephrologists have different experiences from those mentioned in the textbooks about the barriers to high - quality dialysis. Sehgal (26) and Palevsky (23) in their studies after mentioning physiological causes such as duration $<4$ hours, BFR $<350 \mathrm{~mL} /$ minute, patient weight $>100 \mathrm{~kg}$, and delivered BFR $50 \mathrm{~mL} / \mathrm{minute}$ less than the proposed BFR for inadequate dialysis suggested further studies to find other barriers to dialysis adequacy. The current study also showed that the experience of patients and health care providers about various hemodialysis barriers were different from the proposed physiological factors.

A qualitative study by Greer extracted the opinions of nephrologists, residents, and nurses on the barriers to appropriate preparation of patients with end - stage renal diseases (ESRD) for kidney transplant through interviews. One of these barriers was lack of understanding and acceptance of the conditions of the disease and its treatment methods by the patient. The participants' experiences in the current study also showed that failure to accept and non - compliance with hemodialysis standards were among the barriers to quality dialysis (27).

Nobahar in a content analysis presented eight categories on the obstacles to hemodialysis care; one of them was "weak authority of the head nurse" (28). In the current study, poor supervision was one of the barriers to high - 
quality dialysis. In addition, "basic knowledge" was considered as a care facilitator that is similar to results of the current study. "Data deficit" was also extracted as a barrier to high - quality dialysis.

Pashaii in a phenomenological study, extracted four themes of hemodialysis life, including 'hemodialysis as an undeniable part of life', 'dialysis life tensions', 'the need for support', and 'effective adaptation' (29). Asgari also developed a grounded theory entitled "Compatibility Model in Patients Undergoing Hemodialysis" with the themes of understanding the threat, hemodialysis and its complications, disease acceptance and hemodialysis, self - esteem, and life management. These themes were the strategies used by participants to return to normal and active life and to adapt to hemodialysis (30). In the current study, lack of acceptance and adaptation to new conditions of life due to undergoing hemodialysis (rejection of hemodialysis) was extracted as a barrier to high - quality dialysis.

The results of many studies, such as those of Kaya (31), El - Sheikh (32), Saran (33), and Al - Yousef (34) showed that dialysis over a standard period of time can improve dialysis quality. Studies revealed that the limited number of dialysis machines in Iran, despite the five-hour dialysis in many parts of the world, curtailed the dialysis duration to three hours. Our results also showed that rapid dialysis (dialysis shorter than the standard time) is one of the most important barriers to adequate dialysis.

The obsoleteness of dialysis machines is one of the biggest problems in patients undergoing hemodialysis in Iran. The data from Iran revealed that $37 \%$ of the dialysis machines have operated more than 20,000 hours, which significantly undermines the quality of dialysis (35). In the current study, the obsolete device was a barrier to high quality dialysis.

In the Fellows Corner, Rope claimed that in most cases, decisions for starting dialysis are made based on the views of families of the patient or care providers, not the patient himself (the author referred to it as 'paternalism') (36). Lederer also conducted a qualitative study on veterans with chronic kidney disease (CKD) and showed that passive behavior and being just a listener are of the barriers to effective communication between patients and healthcare providers (37). In the same vein, the current study revealed that passive behavior is one of the barriers to dialysis adequacy.

One of the challenges in Iran is paying the dialysis costs disregarding the quality of the services. An administrative official said: "Currently, insurers pay the same costs regardless of the quality of treatment and services provided in the departments, which may be one of the most important reasons for low-quality dialysis in Iran" (38). The current study also extracted delayed and unevaluated payment as one of the barriers to high - quality dialysis.

\subsection{Conclusion}

The results of the current study showed that patients undergoing hemodialysis, health care providers, and nephrologists active in this field have different experiences from what is mentioned in textbooks about barriers to high - quality dialysis. The findings of the present study along with the growing annual costs of dialysis in Iran, which is billions of US Dollars, highlight the need for immediate re - examination and preparation of the standards for monitoring the quality of hemodialysis in Iran, as well as the need for attention and focus on non - physiological barriers to dialysis adequacy. They also opened up a new window for authorities in this area to eliminate management barriers and facilitate strong supervision.

Undoubtedly, the current payment method, disregarding the quality of dialysis, cannot provide sufficient financial incentives for efficient and high - quality dialysis in the dialysis centers, which may lead to irreparable harms to patient health in the first place, and then to the national economy.

\section{Acknowledgments}

The article is part of a Ph.D. thesis (code: 941689) approved by Mashhad University of Medical Sciences, Mashhad, Iran. The authors sincerely thank all the participants.

\section{References}

1. Kooman J, Basci A, Pizzarelli F, Canaud B, Haage P, Fouque D, et al. EBPG guideline on haemodynamic instability. Nephrol Dial Transplant. 2007;22 Suppl 2:ii22-44. doi: 10.1093/ndt/gfm019. [PubMed: 17507425].

2. Vanholder RC, Ringoir SM. Adequacy of dialysis: A critical analysis. Kidney Int. 1992;42(3):540-58. doi: 10.1038/ki.1992.318.

3. Saad MM, El Douaihy Y, Boumitri C, Rondla C, Moussaly E, Daoud M, et al. Predictors of quality of life in patients with end-stage renal disease on hemodialysis. Int J Nephrol Renovasc Dis. 2015;8:119-23. doi: 10.2147/IJNRD.S84929. [PubMed: 26366104].

4. Manandhar DN, Chhetri PK, Tiwari R, Lamichhane S. Evaluation of dialysis adequacy in patients under hemodialysis and effectiveness of dialysers reuses. Nepal Med Coll J. 2009;11(2):107-10. [PubMed: 19968150].

5. Curtin RB, Mapes DL. Health care management strategies of longterm dialysis survivors. Nephrol Nurs J. 2001;28(4):385-92. discussion 393-4. [PubMed:12143460].

6. Rezaiee O, Shahgholian N, Shahidi S. Assessment of hemodialysis adequacy and its relationship with individual and personal factors. Iran J Nurs Midwifery Res. 2016;21(6):577-82. doi: 10.4103/1735-9066.197673. [PubMed: 28194196].

7. Malekmakan L, Haghpanah S, Pakfetrat M, Malekmakan A, Alimanesh M, Haghpanah A, et al. Dialysis adequacy and Kidney Disease Outcomes Quality Initiative goals achievement in an Iranian hemodialysis population. Iran J Kidney Dis. 2010;4(1):39-43. [PubMed: 20081303]. 
8. Barzegar H, Moosazadeh M, Jafari H, Esmaeili R. Evaluation of dialysis adequacy in hemodialysis patients: A systematic review. Urol J. 2016;13(4):2744-9. [PubMed: 27576879].

9. Ranasinghe P, Perera YS, Makarim MF, Wijesinghe A, Wanigasuriya K. The costs in provision of haemodialysis in a developing country: a multi-centered study. BMCNephrol.2011;12:42. doi:10.1186/1471-2369-1242. [PubMed: 21896190].

10. Braun L, Sood V, Hogue S, Lieberman B, Copley-Merriman C. High burden and unmet patient needs in chronic kidney disease. Int J Nephrol Renovasc Dis. 2012;5:151-63. doi: 10.2147/IJNRD.S37766. [PubMed: 23293534].

11. Biniaz V, Tayybi A, Nemati E, Sadeghi Shermeh M, Ebadi A. Different aspects of fatigue experienced by patients receiving maintenance dialysis in hemodialysis units. Nephrourol Mon. 2013;5(4):897-900. doi: 10.5812/numonthly.11667. [PubMed: 24350089].

12. Ekramzadeh M, Mazloom Z, Jafari P, Ayatollahi M, Sagheb MM. Major barriers responsible for malnutrition in hemodialysis patients: challenges to optimal nutrition. Nephrourol Mon. 2014;6(6). e23158. doi: 10.5812/numonthly.23158. [PubMed: 25738117].

13. Einollahi B, Motalebi M, Rostami Z, Nemati E, Salesi M. Sleep quality among Iranian hemodialysis patients: a multicenter study. Nephrourol Mon. 2015;7(1). e23849. doi: 10.5812/numonthly.23849. [PubMed: 25738125].

14. Asgari MR, Asghari F, Ghods AA, Ghorbani R, Hoshmand Motlagh N, Rahaei F. Incidence and severity of nausea and vomiting in a group of maintenance hemodialysis patients. J Renal Inj Prev. 2017;6(1):49-55. doi: 10.15171/jrip.2017.09. [PubMed: 28487872].

15. Jalalzadeh M, Nazarian M, Vafaeimanesh J, Mirzamohammadi F. Comparison of azithromycin and clarithromycin triple therapy regimens for helicobacter pylori eradication in hemodialysis patients. Nephrourol Mon. 2012;4(3):571-7. doi: 10.5812/numonthly.2794. [PubMed: 23573488].

16. Shahgholian N, Dehghan M, Mortazavi M, Gholami F, Valiani M. Effect of aromatherapy on pruritus relief in hemodialysis patients. Iran J Nurs Midwifery Res. 2010;15(4):240-4. [PubMed: 22049288].

17. Hakeshzadeh F, Tabibi H, Ahmadinejad M, Malakoutian T, Hedayati M. Effects of L-Carnitine supplement on plasma coagulation and anticoagulation factors in hemodialysis patients. Ren Fail. 2010;32(9):110914. doi: 10.3109/0886022X.2010.510617. [PubMed: 20863217].

18. Biniaz V, Nemati E, Tayebi A, Sadeghi Shermeh M, Ebadi A. The effect of vitamin $C$ on parathyroid hormone in patients on hemodialysis with secondary hyperparathyroidism: a double blind, placebo-controlled study. Nephrourol Mon. 2013;5(5):962-6. doi:10.5812/numonthly.12404. [PubMed: 24693502].

19. Omrani VF, Fallahi S, Rostami A, Siyadatpanah A, Barzgarpour G, Mehravar S, et al. Prevalence of intestinal parasite infections and associated clinical symptoms among patients with end-stage renal disease undergoing hemodialysis. Infection. 2015;43(5):537-44. doi: 10.1007/s15010-015-0778-6. [PubMed: 25869822].

20. Ahmadieh A, Baharvand M, Fallah F, Djaladat H, Eslani M. Oral microflora in patients on hemodialysis and kidney transplant recipients. Iran J Kidney Dis. 2010;4(3):227-31. [PubMed: 20622312].

21. Gordon EJ, Leon JB, Sehgal AR. Why are hemodialysis treatments shortened and skipped? Development of a taxonomy and relationship to patient subgroups. Nephrol Nurs J. 2003;30(2):209-17. discussion 218. [PubMed: 12736999].

22. Abdelwahab HH, Shigidi MM. Barriers to adequate urea clearance among hemodialysis patients in developing countries: an example from the Sudan. Saudi J Kidney Dis Transpl. 2015;26(1):144-8. [PubMed:
25579738].

23. Palevsky PM, Washington MS, Stevenson JA, Rohay JM, Dyer NJ, Lockett $\mathrm{R}$, et al. Barriers to the delivery of adequate hemodialysis in ESRD Network 4. Adv Ren Replace Ther. 2000;7(4 Suppl 1):S11-20. [PubMed: 11053582].

24. Hsieh HF, Shannon SE. Three approaches to qualitative content analysis. Qual Health Res. 2005;15(9):1277-88. doi: 10.1177/1049732305276687. [PubMed: 16204405].

25. Guba EG, Lincoln YS. The Sage Handbook of Qualitative Research Paradigmatic Controversies, Contradictions, and Emerging Confluences. In: Denzin NK, Lincoln YS, editors. 3rd ed. Thousand Oaks: Sage; 2005. p. 191-215.

26. Sehgal AR, Snow RJ, Singer ME, Amini SB, DeOreo PB, Silver MR, et al. Barriers to adequate delivery of hemodialysis. Am J Kidney Dis 1998;31(4):593-601. [PubMed: 9531174].

27. Greer RC, Ameling JM, Cavanaugh KL, Jaar BG, Grubbs V, Andrews CE, et al. Specialist and primary care physicians' views on barriers to adequate preparation of patients for renal replacement therapy: a qualitative study. BMC Nephrol. 2015;16:37. doi: 10.1186/s12882-015-0020-x. [PubMed: 25885460].

28. Nobahar M, Tamadon MR. Barriers to and facilitators of care for hemodialysis patients; a qualitative study.J Renal Inj Prev. 2016;5(1):3944. doi: 10.15171/jrip.2016.09. [PubMed: 27069967].

29. Pashaii Sabet F, Nikbakht Nasrabadi A, Karami Kabir N. Life with hemodialysis unit: A phenomenological study. Iran J Crit Care Nurs. 2011;4(2):66-59. Persian.

30. Asgari MR, Mohammadi E, Fallahi Khoshkbab M, Tamaddon MR. Perception of chronic renal failure patients from advocacy resources in adjustment with hemodialysis: A qualitative study. Iran J Crit Care Nurs. 2010;3(4):133-42. Persian

31. Kaya T, Sipahi S, Cinemre H, Karacaer C, Varim C, Nalbant A, et al Relationship between the target dose for hemodialysis adequacy and nutritional assessment. Ann Saudi Med. 2016;36(2):121-7. doi: 10.5144/0256-4947.2016.3.4.1735. [PubMed: 27038739].

32. El-Sheikh M, El-Ghazaly G. Assessment of hemodialysis adequacy in patients with chronic kidney disease in the hemodialysis unit at Tanta University Hospital in Egypt. Indian J Nephrol. 2016;26(6):398404. doi: 10.4103/0971-4065.168141. [PubMed: 27942169].

33. Saran R, Canaud B], Depner TA, Keen ML, McCullough KP, Marshall MR, et al. Dose of dialysis: key lessons from major observational studies and clinical trials. Am J Kidney Dis. 2004;44(5 Suppl 2):47-53. [PubMed: 15486874]

34. AlYousef A, AlGhareeb S, Al Wakeel J, Al-Ghamdi SM, Bieber BA, Hassan $M$, et al. Hemodialysis delivery, dialysis dose achievement, and vascular access types in hemodialysis patients from the Gulf Cooperation Council countries enrolled in the dialysis outcomes and practice patterns study phase 5 (2012-2015). Saudi J Kidney Dis Transpl. 2016;27 Suppl 1:S42-50. doi: 10.4103/1319-2442.194889. [PubMed: 27991478].

35. Farse news . 1500 Dialysis machine is needed in the country. News code: 13940820001036. 2015. Available from: http://www.farsnews. com/printable.php?nn=13940820001036.

36. Rope R. Dialysis Decision-Making: Can We Help Patients and Providers through the Process? ASN Kidney News. 2017.

37. Lederer S, Fischer MJ, Gordon HS, Wadhwa A, Popli S, Gordon EJ. Barriers to effective communication between veterans with chronic kidney disease and their healthcare providers. Clin Kidney J. 2015;8(6):766-71. doi: 10.1093/ckj/sfv079. [PubMed: 26613037].

38. Mortazavi N. The need to review in insurance policies. Dialysis monthly. 2016;12(125):1-2. Persian. 